\title{
FLUIDOS, TENDÕES, CARNES E TENSÕES: O AVESSO NEGRO DO CORPO
}

\begin{abstract}
Fernanda Miranda da Cruz é professora da Escola de Filosofia, Letras e Ciências Humanas, Universidade Federal de São Paulo-UNIFESP, Guarulhos-SP. É doutora em Linguística (2008) pelo Instituto de Estudos da Linguagem- UNICAMP, Campinas. Seus temas de pesquisa transitam entre o debate clássico e vigente sobre as relações entre o social e biológico atravessado pelo contemporâneo e pelos discursos sobre o corpo. Coordena desde 2010 o NUCCA- Núcleo de Cultura, Corpo e Arte na UNIFESP. O objetivo deste é explorar, do ponto de vista prático, artístico e teórico, as múltiplas significações e formas de ser do corpo na sociedade urbana contemporânea.

E-mail: (fernanda.cruz@unifesp.br)
\end{abstract}

Resumo: Nos propomos a gerar um conjunto de linhas de reflexão sobre formas de representação contemporâneas do corpo através de terrenos variados como a biotecnologia, as marchas de rua e algumas expressões artísticas.
Abstract: We propose to generate routes of reflection on contemporary forms of representation of the body through varied terrain such as biotechnology, street marches and some artistic expressions.

"Ao revelar o que deve permanecer oculto, o corpo monstruoso subverte a mais sagrada das relações entre a alma e o corpo: a alma revelada deixa de ser uma alma, torna-se, no sentido próprio, o reverso do corpo, um outro corpo, mas amorfo e horrivel, um não-corpo."

José Gil, Monstros

\section{1) $O$ corpo por dentro: o que se quer ver e o que se pode ver}

Uma característica do século XIX são as inovações nas técnicas de visualização. Estas técnicas de visualização ou visibilidades também revestem aquele século de novos métodos de visão, o que implica, por sua vez, outros lugares e outro papel para o observador do corpo humano. Em 1895, enquanto a ciência da imagem e do diagnóstico dariam um passo importante para o conhecimento do corpo, com o advento do raio-X, outro movimento, ou talvez o mesmo, também estava às voltas com o conhecimento humano através de uma espécie de raio-x para o interior da mente, a psicanálise. Duas descobertas ou movimentos das ciências oriundos do campo da biomedicina ocorridos no século XIX, o raio-X e a psicanálise apontam a tentativa de entrada no conhecimento do ser humano, ora pelo corpo, ora pela mente, ora pela desejada unidade entre essas duas dimensões. Certamente não temos dúvida da incrível importância dessa descoberta e das pesquisas no campo das imagens para a investigação e práticas médicas. Mas o que chamaria a atenção para as primeiras imagens reproduzidas do interior do corpo vivo é que tal imagem se apresentava como um esqueleto, como a figura icônica da morte (Cartwright, 1995, p.121). A possibilidade de entrada, através do olhar, no interior do corpo parece reorganizar o olhar sobre este: uma materialidade para o corpo salta aos olhos e é quase impossível não pensarmos "somos isto?", "somos o corpo?". Com isso, a história da descoberta, dos usos e das repercussões do raio-X revela não apenas os novos cenários que se abrem para a investigação e para diagnóstico, mas também os medos, anseios 
e crenças de uma época.

O corpo radiografado apaga qualquer possibilidade de movimento ou expressão humana. Mas seria ele mais acessível ao olhar do que o corpo dissecado por que lhe esconde a carne, as entranhas, os fluidos, a dor? Ou por que embora pareça revelar um corpo esqueleto, ícone da morte, também revela um corpo limpo e estático? Esse corpo radiografado familiariza o olhar com o interior simplificado a ponto de não enxergamos as subjetividades, fluidos, temperaturas, humores, barulhos e movimentos. Ele revela o interior, mas sua imagem externaliza o sujeito, coloca-o para fora dele ou para lugares ainda mais internos que não podem ser vistos. A atenção não está sobre o corpo, mas sobre o "radiografado" e o método. Ele instaura-se numa época em que mais vale o desenvolvimento do conhecimento das técnicas de visualização do que a multiplicidade de modos de olhar o corpo e o humano.

\section{1) Ainda dentro do corpo: "o avesso negro do corpo"}

A imagem produzida parece chamar mais a atenção para si e para as técnicas de se produzir essas imagens do que para o objeto "corpo" no mundo. O objeto agora é imagem do corpo e não o corpo. Isso parece externalizar também o corpo e colocar todas as fichas em sua observação, pesquisa e investigação. $\mathrm{O}$ que teria sido inaugural com relação à linguagem para aquilo que representaria a clínica do século XIX? Surge, como nos dirá Foucault uma "articulação da linguagem médica com seu objeto", mas o que muda é uma postura, uma forma de se colocar diante da escuta:

Não houve "psicanálise" do conhecimento médico, nem ruptura mais ou menos espontânea dos investimentos imaginários; não foi a medicina "positiva" que fez uma escolha "objetal" apoiada finalmente na própria objetividade. Nem todos os poderes de um espaço visionário através do qual se comunicavam médicos e doentes, fisiólogos e práticos (nervos tensos e torcidos, secura ardente, órgão endurecidos ou queimados, novo nascimento do corpo no elemento benéfico do frescor e das águas) desapareceram; foram antes deslocados e como que encerrados na singularidade do doente, na região dos "sintomas subjetivos" que define para o médico não mais o modo do conhecimento, mas o mundo dos objetos a conhecer. $O$ vínculo fantástico do saber com o sofrimento, longe de se ter rompido, é assegurado por uma via mais complexa do que a simples permeabilidade das imaginações; a presença da doença no corpo, suas tensões, suas queimaduras, o mundo surdo das entranhas, todo o avesso negro do corpo, que longos sonhos sem olhos recobrem, são tão contestados em sua objetividade pelo discurso redutor do médico, quando fundados como objetos para seu olhar positivo. As figuras da dor não são conjuradas em benefício de um conhecimento neutralizado; foram redistribuídas no espaço em que se cruzam os corpos e os olhares. O que mudou foi a configuração surda em que a linguagem se apoia, a relação de situação e de postura entre o que fala e aquilo de que se fala." (Foucault, 1980, p. 09, grifos do autor.)

A medicina do século XIX desloca o lugar de um saber médico baseado em um método prático e empírico, para um saber médico positivo, mediado por um discurso científico sobre o corpo e suas patologias. Mas técnicas e visualizações do corpo, herdeiras desta vontade de verdade científica sobre o corpo, vão, do raio-X às sofisticadas técnicas digitais contemporâneas, produzindo cada vez mais imagens dificilmente associáveis a qualquer possibilidade de corpo minimamente reconhecível por um olhar leigo. $\mathrm{O}$ raio-X ainda permite 
um reconhecimento do sujeito do corpo; seja ele por um esqueleto, seja ele por formas que nos deixam, ao menos, resgatar, nas estruturas ósseas, os contornos de um corpo humano. De uma prática anterior empírica de se dissecar o corpo para ver o que lhe acontece, movida pela palavra de ordem "abram-se os cadáveres", para fazer alusão a um dos capítulos homônimo do Nascimento da Clínica, passamos ao desenvolvimento e aprimoramento de técnicas visualização de corpos fechados. A investigação biomédica deixa de dissecar os corpos para poder ver seu interior, mas teve como ônus a dissecação do olhar sobre os corpos. A nova palavra de ordem passa a ser "abram-se os olhos". O método vence o objeto.

Um movimento de olhar para o interior também surge ou é mobilizado com a psicanálise no mesmo ano em que o raio-X é descoberto. Em 1895, Freud traz a público suas lições de psicanálise. Um método de entrada também em lugares obscuros do sujeito elegendo a mente, mas também o corpo em movimento. O método aqui desloca-se do olhar para a escuta. Que deslocamento poderia ser esse senão o da própria linguagem no campo da patologia e do método clínico dos fins do século XIX e ao longo de todo século XX? Um deslocamento para a "singularidade do doente e para a região dos "sintomas subjetivos" e uma nova relação estabelecida, a do que fala com o que se fala: "abram-se os ouvidos".

Talvez pudéssemos dizer que a maioria, senão todos os métodos de investigação apoiam-se nestes dois sentidos: o que se pode ver (evidência) e que se pode escutar. Mas se quem vê e ouve ou fala o próprio corpo for o sujeito desse corpo? Essas evidências seriam mais suscetíveis de serem permeadas por subjetividades? Mas se quem vê são métodos e tecnologias científicos capazes de dar precisão à descrição do que se vê, o corpo é então objeto a ser conhecido por esse outro sujeito detentor do saber científico sobre o corpo. O corpo é tornado objeto de observação e pode descolar-se do sujeito que o habitaria. Salvo do sujeito, o corpo estaria no foco. Isso parece não passar indiferente pelas formas de olhar o próprio sujeito. Onde teria ido parar o sujeito? Os avanços tecnológicos, sobretudo das imagens digitais, escaneiam cada vez mais os recantos mais impensáveis do corpo, capazes de capturar os caminhos e seus fluxos, os depósitos de placas ou sedimentos, as corrosões, as fissuras, as anormalidades. Todo este conjunto de imagens de corpo aproxima de tal forma as dimensões tecnológicas e biológicas que parecem também reorganizar as clássicas fronteiras entre o natural e o artificial (Chazan, 2001).

Como dito, essas imagens, mais representativas para a investigação científica do que aconteceria realmente com o corpo, parecem mais distantes de nossas possibilidades enquanto leigos de vermos ou lermos o que acontece com esse corpo a partir dessas imagens. Na linha do pensamento de Rose (2007), em seu "The politics of life itself: biomedicine, power, and subjectivity in the twenty-first century", que considera aquilo que nomeia como molecularização um dos processos das mudanças biopolíticas contemporâneas, podemos identificar como essa molecularização incide num plano epistemológico, partindo do saber biomédico e deslocando a reflexão sobre a vida para o nível molecular. Esse deslocamento do pensamento sobre a vida, entendida como uma articulação de moléculas, insere-nos em um 
universo de possibilidades de associações, dissociações, experimentações, manipulações, recombinações nesses níveis mais complementares que fundam outros parâmetros para o que é natural e artificial, entre o que é real e virtual. Como analisa Ortega (2008):

"na tecnobiomedicina contemporânea, os corpos são progressivamente virtualizados. O uso crescente de novas tecnologias de visualização, associado ao desenvolvimento de anatomias e clínicas virtuais, se adequa a uma prática médica cada vez mais digitalizada, levando a ultrapassar os limites entre o corpo real e o virtual." (Ortega, 2008, p.51).

Para além disso, outros saberes são construídos e necessários para a leitura das representações do corpo humano. Se as imagens do corpo passam a ser a entrada para o conhecimento, ou um tipo de conhecimento, sobre o corpo, mais sujeitos ignorantes (que desconhecem o corpo) são produzidos. O sujeito não apenas fica fora de seu corpo como o desconhece e o ignora. As figuras leigos e experts do corpo passam a servir também às figuras do leigo e dos experts da vida humana. Eis uma pontinha visível de onde o saber e não-deixarsaber exercem sua força. Eis o binômio caro a Foucault saber-poder. Os conceitos, métodos, instrumentos inibem as possibilidades de conhecer o corpo através de uma existência corpórea que não seja mediada por discurso científico sobre o corpo. Funda-se um humano meramente humano, despotencializado. Certamente as tecnologias da imagem parecem dizer que há mais possibilidades de olhar do que o olho e a percepção nos oferecem. Mas o próprio sujeito parece também ter nos informado sobre isso. Cada método de visão e de apreensão sobre o corpo revelará o corpo aprisionado pelo discurso desse método. $\mathrm{O}$ avesso negro do corpo teria suas razões para se mostrar negro? Para não se deixar ver? Seria preciso abrir mais ainda os olhos e ouvidos? São às limitações de método a que devemos nos reportar para reclamarmos que esse corpo ainda permanece para nós um desconhecido? Quais métodos deverão ser inventados para dar conta das camadas corpóreas mais profundas para onde relegamos o sujeito do corpo?

\section{2) $O$ interior acessível: as imagens e as sensações da carne}

Se o corpo representado pelas imagens produzidas pelas biotecnologias produzem corpos desencarnados, sem dores, fluidos, fluxos, sangues e barulhos, temos que as tecnologias das imagens corpóreas tornam mais misterioso o corpo porque não o deixa legível ao sujeito que possui. $\mathrm{O}$ corpo reservado passa então a ser o objeto de desejo de saber, ou de uma vontade de saber, como nos dirá Foucault, do próprio ser que o contém. A chamada arte carnal, nas expressões de Orlan e Stelarc, aponta para essa vontade de saber do corpo, para a vontade de nele entrar e expandir suas possibilidades. Esses dois artistas contemporâneos reconfiguram conceitual, artística e fisicamente seus corpos inspirando-se e utilizando-se das intervenções das biotecnologias contemporâneas.

Orlan, por exemplo, parte de um repertório de seu tempo como cultura, diferenças, liberdade, o direito sobre o próprio corpo, tecnologias, e o corpo como objeto político e estético para suas obras plásticas e performances. Um elemento característico das criações artísticas de Orlan são as performances cirúrgicas a que se submete a artista. Preparem os 
olhos: eu abro meu corpo. Nas performances videoexibidas em museus, o corpo é um suporte de intervenções sem a dor do sujeito (o artista) que o habita e o observa ao mesmo tempo. $\mathrm{O}$ elemento da dor é apagado mesmo quando o corpo vivo é aberto e suas entranhas e fluxos revelados. Em que lugar ficariam então as dores, as sensações? Que corpo é esse que permite colocar em camadas cada vez mais profundas aquilo que não resolvemos bem? Em um manifesto intitulado Arte Carnal, Orlan sugere que acessar o interior do corpo não significa necessariamente passar pela dor "I can observe my own body cut open without suffering !..." Os desejos de abolir a dor são reencontrados na publicidade farmacêutica contra toda e qualquer dor. No manifesto, Carnal Art é definido pela própria artista, como "self-portraiture in the classical sense, but realized through the possibility of technology".

Distinto da Body Art, a Carnal Art não pretende mostrar a dor, ao contrário, faz um elogio às substâncias que inibem as dores "Vive la morphine! (down with the pain!) A bas la douleur !". Nem se interessa particularmente pelo resultado da cirurgia plástica, mas, pelo "process of surgery, the spectacle and discourse of the modified body which has become the place of a public debate." Orlan parece nos dizer, vejam como é possível acessar o corpo.

O performer Stelarc parece colocar a dor em outro plano. Explorando criativamente as relações entre artes visuais e tecnologia, tanto no plano artístico como conceitual, Stelarc, por vezes, causa espanto no público ao apresentar suas performances que em seu corpo suspensos por ganchos presos na pele é alçado diante dos olhos da plateia. Novamente: preparem os olhos, eu abro meu corpo. Que dor há ali? Mas Stelarc antecipa-se em sua concepção de que o corpo é obsoleto. Em um dos trabalhos intitulado Third Hand, Stelarc implanta uma terceira mão em seu braço direito a partir de um protótipo projetado para suas performances. A terceira mão não substitui a mão direita, mas ao contrário expande as possibilidades, capacidades do corpo, não apenas de movimento, mas também de percepção e sensações, aumentando assim sua potência a partir de uma experiência cyborg. Expansão de potência para o corpo que não mais ${ }^{1}$. A modificação corporal não passa apenas por uma estética, mas por uma experiência completamente sensível do artista desta modificação. Neste projeto, Stelarc implantará, anos depois, uma orelha em seu antebraço esquerdo.

Conceitualmente, Stelarc desenvolve sua tese de que a tecnologia constrói nossa natureza humana. Mas, como reforça Hall (2002), Stelarc não supõe que haja metafísica ou biologicamente um corpo humano natural, mas que as relações entre humano e tecnologias ou artefatos embora sempre existentes, são distintas a depender das épocas:

"different technologies make possible different ways of conceiving this relation at different
times" (...) What Stelarc performs with his investigations into how different developments in
technology (robotics, the Internet, virtual reality systems, prosthetics, medical instruments and
procedures) alter our conception of the human and of the human body, is the way in which
technology escapes the control of its inventors to produce unseen and unforseeable changes

1 Aqui faço uma alusão a discussão proposta por David Lapoujade. Provavelmente um próximo caminho desta discussão apresentada aqui. LAPOUJADE, David. O corpo que não agüenta mais. In: LINS, Daniel; GADELHA, Sylvio (Orgs.). Nietzsche e Deleuze: que pode o corpo. Rio de Janeiro: Relume Dumará, 2002. p. 82-90 
and possibilities; and thus a future - for the self, the human, for the body and for technology which can be neither programmed nor predicted. (Hall, 2002, p. 140).

A experiência estética de Orlan nos leva a entrar nas camadas cada vez mais obscuras e desconhecidas pelo próprio sujeito do corpo graças às tecnologias de que dispomos. Mas o acesso a essas camadas precisa levar as dores e as sensações a camadas mais obscuras e inacessíveis. Preparem as carnes. O sujeito que se apropria do próprio corpo através da apropriação das técnicas e do discurso científico teria de abrir mão das dores e sensações deste corpo? A anestesia poderia ser metaforicamente o sujeito desencarnado ou ainda a carne sem espírito? A experiência estética de Stelarc nos leva a reflexões que se seguem neste caminho. As tecnologias, que permitem uma expansão dos limites do corpo, também revelam que este corpo é obsoleto. Sua potência é aumentada fora dele, ele mostra-se obsoleto em sua própria capacidade de se superar. Ao mesmo tempo haveria uma superação do ser humano a partir dessas experiências tecnológicas?

Se no desenvolvimento das técnicas de visualização do corpo, novos olhares se criam sobre este, com o avanço das biotecnologias já não é mais só possível olhar o corpo, mas nele intervir. Esses movimentos chamam a atenção para o fato de que o corpo é um objeto sobre o qual interveem sistemas de forças, ações, mecanismos de controle, tecnologias e sujeitos. Esses corpos, suportes da própria arte e não mais objetos de discurso da arte, são colocados em situações possíveis e familiares, quase cotidianas, mas ao mesmo tempo, estranhas e provocadoras. O corpo na contemporaneidade, como propõem os dois artistas, é obsoleto. Que corpo é esse? A que serve este corpo? As perguntas devem recair menos sobre que corpo é esse e mais sobre a época presente que age, de certas formas, sobre os corpos.

\section{3) $O$ corpo em evidência: as corporeidades em movimento}

Culto ao corpo, fisioculturismo, cirurgias plásticas, intervenções estéticas, tatuagens, piercings, próteses, medicamentos contra envelhecimento, contra gorduras, controles e dietas alimentares, manuais de condutas para viver bem e para cuidar do corpo são exemplos flagrantes de que o corpo está, de alguma forma, em evidência.

Esses exemplos também significam um conjunto de práticas contemporâneas que revelam o corpo como um lugar privilegiado para a ação de práticas prescritivas ao longo das épocas. Às ações prescritivas estão subjacentes discursos de saber, autoridades, modelos de existência e, portanto, uma moral datada. Mas essas ações prescritivas se vistas como um poder invisível reduziriam nossa análise a dois aspectos importantes: um deles, como recairia sobre o corpo um conjunto de ações; e o outro, como essas ações e essas práticas também mobilizariam a construção ou a possibilidade de (novas?) subjetividades. Para tentar apontar aqui brevemente um universo de reflexões mais complexo seria preciso esboçar pelo menos dois caminhos que nos ajudariam a não reduzir nossa tentativa de entendimento do estatuto do corpo na contemporaneidade a uma conclusão de que corpo seria um objeto sempre controlado por outra força externa. Esses dois caminhos seriam: entender como atuam as ações de poder e 
admitir a existência de processos de construção de bioidentidades contemporâneas.

Para o primeiro caminho, precisamos supor uma noção de poder distinta daquela que o entende como uma ação exercida unilateralmente do mais forte sobre algo ou alguém mais fraco. Precisamos supor antes a ideia de um sujeito moral ativo diante das práticas prescritivas e um entendimento do que seria uma moral:

(...) toda ação moral implica uma relação com o real que ela se realiza, e uma relação com o código ao qual ela se refere; mas também implica uma certa relação consigo mesmo; esta não é simplesmente 'consciência de si', mas constituição de si como sujeito moral, na qual o indivíduo circunscreve a parte dele próprio que constitui esse objeto de prática moral, define a sua posição em relação ao preceito que ele acata..."( Foucault, 1985, 213).

Foucault, em Sujeito e Poder, apresenta uma forte tese de que o poder só se exerce sobre sujeitos livres e que não haveria um antagonismo entre poder e liberdade, mas um "agonismo" (combate), "uma relação de incitação recíproca e de luta de forças". Assim sendo, não é preciso tomar como oposição poder x liberdade. Esta última, a liberdade, seria uma condição mesma para a existência do poder. Todas as pistas ali, na liberdade. Não se busca esta coisa desejante, não se prescreve, se exerce, como dirá Foucault do cuidado de si. Todas as pistas aqui, mas ainda é de poder que se fala... Relacionado a isso, concebemos que os processos de construção de bioidentidades, estariam pautados, na "formação de um sujeito que se autocontrola, autovigia e autogoverna". Uma característica fundamental dessa atividade seria a auto-peritagem: "o eu que se "pericia" tem no corpo e no ato de se periciar a fonte básica de sua identidade" (Ortega, 2008, 33). Assim o autocontrole, ou uma espécie de perícia somática (Rose, 2006), traz como prescrição aqueles saberes que deveriam ser do sujeito, como "escutar o corpo", "saber os sinais do corpo", "cuidar do próprio corpo". Paradoxalmente, enquanto os saberes e os métodos de investigação sobre os corpos ficam a cargo de um poder e de um saber biomédico, ao sujeito caberia a culpa do não cuidado de si, justamente por desconhecer os saberes que lhe foram outrora amputados. $\mathrm{O}$ autocontrole da saúde não apenas responsabiliza o sujeito pela própria vida, como o culpa de seu risco de morte. Assim, a construção de um sujeito que deve se preocupar com a própria vida está longe de admitir um sujeito livre que cuida de si como forma de liberdade, mas como um sujeito moral. Vamos tentar entender então esse aspecto moral como:

“... a maneira pela qual eles se submetem mais ou menos completamente a um princípio de conduta, pela qual obedecem ou resistem a uma interdição ou a uma prescrição, pela qual respeitam ou negligenciam um conjunto de valores; o estudo desse aspecto da moral deve determinar de que modo, e com que margem de variação ou de transgressão, os indivíduos ou grupos se conduzem em referência a um sistema prescritivo, que é explícita ou implicitamente dado em sua cultura, e do qual eles tem consciência mais ou menos clara." (Foucault,1985, p. 211)

E neste jogo então haveria alguma margem de variação ou transgressão dessa moral? À morte antecede a agonia. Corpos agonizantes, mas também luta, liberdade nas relações de poder. 
Contemporaneamente também temos visto um conjunto significativo de movimentos políticos e artísticos que elegem o corpo como o centro de campo visual. Nesses movimentos o que identificamos é justamente um discurso sobre liberdade, que passa centralmente pela apropriação do próprio corpo pelo sujeito que contém. Falamos aqui de movimentos políticos como a Marcha das Vadias e a Marcha do Parto Humanizado, que elegem o corpo como centro das reivindicações. Inscritos nos próprios corpos ou em cartazes, encontramos enunciados que dialogam com um conjunto de práticas e crenças culturais veiculados em discursos cotidianos e institucionais, como: "não vim de sua costela, você que veio do meu útero"; "lugar de mulher é onde ela quiser"; "nem vitimas, nem submissas, livres"; "se ser livre é ser vadia, somos todas vadias"; "nem santa, nem puta. Livre." De forma semelhante, temos a Marcha do Parto Humanizado, em que as mulheres também vão às ruas e protestam contra o biocontrole sobre o corpo e contra a imposição da cesariana, parto com intervenção cirúrgica. Elas também carregam cartazes ou inscrições no próprio corpo, como “Toda gestante tem direito de liberdade, autonomia, estar livre de coerção. Ninguém pode deter você ou seu bebê", "O corpo é meu, o parto é meu"; "O parto é da mulher e não do médico".

Dos movimentos de protesto, de criação e subversão aos movimentos que seguem ondas mais normalizadoras do corpo hoje, como os cultos ao corpo e o disciplinamento deste, o que não parece possível negar é justamente a centralidade do corpo na sociedade contemporânea. Abram-se os olhos, abram-se os ouvidos, preparem-se: nós queremos nosso corpo de volta. Esse centralismo redimensiona um conjunto de práticas que recaem sobre o corpo, tais como as práticas médicas, científicas, tecnológicas, sociais e políticas. As lutas pela libertação do corpo ou de reapropriação do corpo pelo sujeito carregariam uma potência de tornar o corpo mais visível do que a pretensa objetividade científica, que ao tentar o revelar, o apagou ou o tornou opaco?

\section{4) Invertendo o que se vê de fora: o corpo estranho e as outras anatomias possíveis}

Outros traços para a visualização do corpo também são exploradas no campo artístico em que formas e movimentos criados se revelam familiares e estranhos. No entanto, o que parece chamar muita atenção é que elas deixam ver ou querem mostrar algo de humano que não estaria na dependência completa de uma forma padronizada, mas que aceita suas deformações. Em um primeiro cenário, vamos instalar as esculturas da artista plástica japonesa Chie Aaoki, que revelam corpos em transformação, com a fusão de formas humanas e bolhas gigantes. O que se transforma em que? Bolhas se transformariam em seres humanos ou seres humanos se transformariam em bolhas? Ou ainda estas são apenas imagens imediatas que estamos predispostos a interpretar uma vez que partimos do pressuposto de que seres humanos são passíveis de se transformarem em qualquer coisa, em suma, de se transformarem?

A anatomia dos membros inferiores esculpidas pela artista não parece deixar dúvidas de que são humanos, mas uma outra anatomia parece proposta no conjunto da forma. Que corpo é este que parece preso em uma bolha que ele carrega? Ou que bolha é essa que absorve 
os membros superiores, a face, a cabeça de um corpo humano? Que relação ele estabelece com este espaço bolha que ao mesmo tempo o absorve e se funde a ele? Nestas esculturas, está impressa uma nítida sensação de movimento. E esse movimento não deixa explicito se é o ser humano que se transforma em bolha ou se esse mesmo ser humano se origina da bolha. Assim, o movimento reorganiza as rotas.

Então, a proposta aqui é reorganizarmos a rota feita acima entrando no universo artístico da dança. Por quê? Para não ficarmos com a sensação de que querer um corpo de volta nos remete necessariamente a um passado bom em que, um dia, o corpo teria sido nosso. Vamos então experimentar sair, brevemente, dos limites do espaço e do tempo. Como afirma Kuniich Uno (2012), na linha de um pensamento deleuziano:

"o movimento da dança não somente desloca ou "desterritorializa" a imagem do corpo ao introduzir em outra dimensão (que pode ser a do corpo sem órgãos que a atravessa), mas essa imagem revela também uma imagem de tempo sem medida que iguala a ordem ou as ordens da vida vivida pelo corpo fora dos padrões. Estamos portanto dentro e diante de um imenso caos, mas também dentro e diante dos cristais que correspondem a esse corpo, a essa vida, a seu tempo." (Uno, 2012, p.15)

Os trabalhos criados pelo grupo de dança Sintoma, em São Paulo, também propõe espécies de esculturas dançantes estranhas, muito semelhantes às vistas acima, mas em movimento corporal, fruto do projeto intitulado "Mutações". Essa criação artística nos convida a sair das referências mais fixas. Em um dos trabalhos, temos três formas volumosas e coloridas, esticadas ao chão, dispostas uma ao lado da outra. Ouve-se uma respiração forte e ritmada que parece indicar que há algo semelhante a uma forma viva. Guiadas pela composição musical de variações intitulada Rancho dos Transtornados, do artista paulistano Enrique Menezes, vemos uma projeção de formas distintas e movimentos coreografados tomar corpo. O estranhamento das formas dá lugar a breves relances de formas familiares.

Em outro cenário, uma massa amorfa colorida no chão, sem movimentos. Aos poucos essa massa amorfa move-se lentamente, com alterações de volumes e movimentos que culminam na expulsão de uma forma semelhante em proporções menores. A expulsão nos remete a um nascimento doloroso. Na sequência, o ser nascido é novamente engolido pela forma que o gerou. Em mais um cenário, o terceiro, um corpo móvel, com duas cabeças, três apoios e uma bengala luta com o meio duplo que não é um, mas é uma unidade. Reconhecemos semelhanças com a forma humana, no entanto, não parece humano. O lugar de encontro destas das duas cabeças é o desejo por uma única cadeira instalada no centro da cena. Metáfora de um lugar no mundo? Metáfora de um objeto desejado? Lugar de descanso para o corpo com sua bengala que se move de forma custosa? A conquista do único objeto de desejo separa o corpo duplo. Apenas a morte é capaz de revelar os dois e a unidade viva que existia somente no duplo. Agonizante, o corpo partido movimenta-se em espasmos, últimos movimentos tensos da força vital. "Uma criatura viva quer antes de tudo dar vazão a sua força, a própria vida é vontade de potência” (Nietzsche, 1886). O método precisa ir à vazão.

$\mathrm{O}$ que haveria de comum a esses cenários de cores vivas de formas plásticas singulares 
em movimento? Gestos de ruptura, de rompimentos, de partição. Conflitos do duplo que habitam a mesma matéria e morte da unidade ao revelar-se a ambiguidade.

E ainda resta algo a saber: o que os corpos limpos do Raio- $x$, os corpos molecularizados das biotécnicas digitais, os corpos despidos das marchas, os corpos abertos de Orlan e Stelarc, os corpos deformados de Chie Aaoki e os corpos estranhos de dança grupo Sintoma teriam em comum?

\section{5) O corpo subversivo: o subterrâneo}

Suspeito que esses corpos e as representações desses corpos mobilizam uma pergunta comum: o que eles provocariam ou abalariam na arquitetura das subjetividades? As formas acima podem ser consideradas todas formas monstruosas. Mas para entendermos o que haveria de monstruoso no que foi trazido aqui será necessário assumir como válidas as várias tradições distintas de uma ampla interpretação do que é monstro.

Aproveitando brevemente um bom apanhado que Magalhães (2003) faz sobre os significados de monstro, podemos reconhecer onde haveria uma monstruosidade nos exemplos que reunimos neste ensaio para pensarmos o corpo na sociedade contemporânea. Do latim monstrare, mostrar, ou monere (advertir, avisar), a palavra monstro carrega, sobretudo no Renascimento, o sentido de revelação ou profecia. Monstrum carregaria aquilo que é espetacular ou ainda refere-se àquele que se mostra para além da norma. O monstro é, por sua ação de se mostrar, subversivo. Canguillhem dirá em sua obra La conaissance de la vie, que "la existence des monstres met en question la vie quant au pouvoir qu'elle a de nous enseigner l'ordre" (Canguillhem, 1965, p.171).

Ao dar-se a ver, o estranho, o monstruoso é generoso. Sua generosidade está em revelar aquilo que normalmente escondemos. Nenhuma exibição lhe é diretamente pedida, mas ele, ao ser, mostra-se. Sujeito, objeto e método podem se aproximar. O monstro transborda sua representação corporal, material ou física. E com esta ação ele movimenta uma ação ainda mais poderosa: ele age sobre aquele que olha. Assim, o tema do corpo não seria indiferente a ninguém justamente por não haver indiferença e sim reconhecimento, que é próprio da estranheza.

Transferiremos então a ideia de corpo para a ideia de corporeidades. Como tal, o corpo não precisa ser nem real, nem ficcional. Mas ele se quer verdadeiro naquela forma e com isto mostra outras possibilidades de verdade. O monstro não é apenas um corpo, mas é um corpo que está condenado a se exibir, a se mostrar, a se dar a ver e, portanto, a se revelar. Mas esta revelação em nada tem a ver com sua existência. Em nada? Hesito em manter esta frase. Esta revelação reverbera sobre o outro, que observa. E, no ato de observar, é completamente absorvido pela constatação aparentemente simplista de surpresa: nossa, isto é possível!

Eis o ponto a que chegamos: o que há ali é possível. É uma existência possível. Ela coloca em risco a outra existência que se quer, ou que se quereria: a de ser normal, a das formas iguais e identificáveis. Em sendo uma forma possível de existência, o monstro coloca 
em xeque também o que haveria dentro daquela forma. E se dentro for o mesmo? Isso já não importa, pois quem foi olhar dentro se revestiu antes de uma advertência (uma das etimologias das palavras monstrum, monere): aprimorou seus métodos para ver melhor o que há dentro, pois lá as luzes são escassas. Quando possível como forma de vida, este corpo desperta outras possibilidades de olhar e de observação e, consequentemente, outras possibilidades de definição do que ele é e do ser que o contém. Interdito pelas normas que estabelecem o que é, como é, como agir, como usar, o sujeito desse corpo, o monstro, coloca o corpo e seu avesso em lugar de destaque para reverter a própria lógica do sujeito.

Ao final deste caminho que propomos acima, sem nenhuma pretensão de dar a entender que ele nunca fora percorrido antes por outrem, foi necessário pensar na produção de um conjunto de discursos de verdades ou vontades de verdade produzidos sobre a vida humana, sobre o corpo e de um conjunto de mecanismos de fabricações sobre aqueles que podem dizer as verdades, aportar tais verdades e agir, a partir destas verdades, sobre os corpos. Orlan e Stelarc, por exemplo, à revelia do discurso do risco, entram no corpo. As mulheres das marchas, à revelia dos olhares, mostraram seus corpos livres. Mas também o Raio-x, à revelia dos fluxos, mostrou um corpo limpo. Tudo indica ainda que a constituição biológica e corporal parecem instrumentos fundamentais das formas de compreensão de si contemporâneas. Esse centralismo corporal, construído ao longo de séculos de comprovações e construções de verdade sobre a constituição biológica do homem, aciona campos políticos, tecnológicos, biomédicos e éticos. O corpo parece colocar uma pedra na questão biológico e social mostrando ou gritando como nossas biossociabilidades (Rabinow, 1996) reinventam essas naturezas. Por fim, o corpo é um campo de disputas, ético e político, capaz inclusive de desconstruir o discurso da naturalização através do próprio biológico. Como objeto, o corpo obriga que os campos do saber se entrecruzem e criem novos discursos de verdade que colocarão as verdades sustentadas no verdadeiro de cada campo em questão. $\mathrm{O}$ corpo, que sempre ali esteve, nos dá pistas e advertências sobre a necessidade da criação de outros saberes para abrigar tantas vontades de verdade conflitantes sobre seu avesso negro.

\section{REFERÊNCIAS BIBLIOGRÁFICAS}

CANGUILLHEM, George. La connaissance de la vie. Paris: Vrin, 1965.

CARTWRIGHT, Lisa. Screening the body. Tracing Medicine's visual culture. London \& Minneapolis: University of Minnesota Press. 1995.

CASELAS, José. Figuras contemporâneas do biopoder. Saberes, Natal, v. 1, n.02, pp.81-92, 2009.

CHAZAN, Lílian Krakowski. O corpo transparente e o panóptico expandido: considerações sobre as tecnologias de imagem nas reconfigurações da Pessoa contemporânea. PHYSIS: Revista Saúde Coletiva. Rio de Janeiro, v.13, n.1, 2003.

FOUCAULT, Michel. O sujeito e o poder. IN: Hubert L. Dreyfus e Paul Rabinow. Michel Foucault. Uma Trajetória Filosófica. Rio de Janeiro: Forense Universitária, pp.231-249. 
1995.

FOUCAULT, Michel. O nascimento da clínica. Rio de Janeiro: Forense Universitária, 1980. FOUCAUlT, Michel. História da Sexualidade. Uso dos Prazeres. Edição Rio de Janeiro: Edições Graal. 1985.

GIDDENS, Antony. Modernity and Self-Identity: Self and Society in the Modern Age, Oxford: Basil Blackwell, 1991.

GIL, José. Monstros. Lisboa, Quetzal Editores. 1994.

HALL, Gary. 'Para-site'. IN: ZYLINSKA, Joanna (org). The Cyborg Experiments: The Extensions of the Body in the Media Age. Continuum: London \& New York, pp139-140, 2002.

KUNIICH, Uno. A gênese de um corpo desconhecido. São Paulo: n-1 Edições, 2012.

MAGALHÃES, Clélia. Os monstros e a questão racial na narrativa modernista brasileira. Belo Horizonte: Editora UFMG, 2003.

NIETZSCHE, Friedrich. Além do Bem e do Mal. São Paulo: Companhia das Letras. Trad. Paulo César de Souza, 2002.

ORLAN, Carnal Art Manifesto. Disponível em http://www.orlan.net/. Acesso em junho de 2012.

ORTEGA, Francisco. O corpo incerto: corporeidade, tecnologias médicas e cultura contemporânea. Rio de Janeiro: Garamond Universitária. 2003

RABINOW, Paul. Essays on anthropology of reason. New Jersey: Princeton University Press. 1996.

ROSE, Nikolas. The politics of life itself: biomedicine, power, and subjectivity in the twenty-first century. Princeton: Princeton University Press. 2007. 